\title{
Performance Analysis of the Operating Room Using Simulation
}

\author{
Qing Niu ${ }^{1}$, Qingjin Peng ${ }^{1}$, Tarek ElMekkawy ${ }^{1}$, Yin Yin Tan ${ }^{1}$ \\ Helga Bryant ${ }^{2}$, Leanne Bernaerdt ${ }^{2}$ \\ ${ }^{1}$ Department of Mechanical and Manufacturing Engineering, \\ University of Manitoba, Winnipeg, MB, R3T, 5V6, Canada \\ ${ }^{2}$ Health Science Centre, Winnipeg, MB, R3A 1R9 \\ "E-mail: pengq@cc.umanitoba.ca
}

\begin{abstract}
The operating room (OR) is one of the most demanding departments in Winnipeg Health Science Center (WHSC). The problems faced to the OR are the long waiting list of patients and the inefficient utilization of human resources and facilities. The OR needs to treat a large variety of patient types versatility and dynamically. A discrete event simulation tool is used for modeling the OR operation. The major work involving in this research includes data collection, simulation modeling, model validation and output analysis. The initial results have shown the simulation potential in the performance improvement of healthcare systems
\end{abstract}

\section{The research background}

This paper analyses the operating room (OR) in Winnipeg Health Science Center (WHSC) using simulation. WHSC is a healthcare centre serving residents of Manitoba, Northwestern Ontario and Nunavut. The OR is one of the most demanding departments in WHSC. The problems of the OR are the long waiting list of patients and the inefficient utilization of resources. Simulation technology is used in this research as a tool for identifying existing problems and for the improvement of decisionmaking. The problem and the bottleneck in the OR are identified firstly based on the simulation. The decision can then be made for the system improvement.

Simulation has been a very useful tool for healthcare systems. Different objectives have been reached for the improvement of healthcare systems using simulation. Several studies reported the organizational benefits and cost savings of applying simulation to hospital planning and scheduling. Other applied simulation effort focused on the operational process flow of specific healthcare delivery units. The main capability of simulation is to analyze what-if scenarios, which allows significant exploration of multiple options, without spending enormous amounts of expense on staffing, training, and equipment [1]. Computer simulation has been an effective tool for operational analysis of the stochastic processes of healthcare delivery [2]. In the last two decades, the use of simulation as a planning and decision-making tool has been spreading rapidly in the healthcare arena. Simulation can model and analyze real-world problems that cannot be successfully approached by other types of analytical techniques.

Simulation has been applied in healthcare with success. Specialized applications targeting emergency rooms and other operation issues at large institutions are well documented [3]. Testing scenarios of changes in processing methods, resources location and scheduling without major physical investment and risk is a key objective in the application of healthcare simulation [4]. For examples, some successful simulation applications in healthcare include: a simulation model of the emergency department in a general hospital to examine patient flows and the patient waiting time [5]; the simulation to estimate the maximum level of demand in an emergency room and the configuration of resources required [6]; a discrete event simulation model to analyze the renal transplant waiting list and to reduce the size of the waiting list [7]; a patient scheduling simulation model to capture four components of outpatient clinic scheduling systems including external demand for appointments, supply of provider timeslots, the patient flow logic and the scheduling algorithm [8]; and a computer simulation model of the hospital layout for the efficient design and use of resources, as well as assist in planning decisions [9].

The simulation model can be used to minimize the need of facilities. A model is used by Baesler [6] to create a curve for predicting the behaviour of the variable patient's time and to estimate the maximum possible demand that the system can absorb. An experiment is conducted in the simulation model to define the minimum number of physical and human resources required to serve the demand. Wiinamaki [10] uses a simulation model to analyze the detailed process of the emergency care centre based on the 
layout, number of rooms and beds, and operation hours.

OR is one of the most demanding departments in hospitals. Simulation models have been used to depict the operation processing and evaluate the possible alternatives to reduce the length of patient stay in the OR to improve the operation in hospitals. Samaha [11] gathered data for 24 hours per day over a seven-day period. Each operation is evaluated through the simulation model. An operation model is built and possible alternatives are simulated by Blasak [12] to allow a medical center to make only necessary changes for reducing the length of patient stay in the hospital.

This paper discusses the performance analysis of the OR at WHSC. Simulation is used as a tool for a better understanding of the patient experience, process performances and staffing inter-relationships. An open and proactive communication between researchers and the hospital staff ensures the right way for the project success. The major work involving in this research includes: data collection; simulation modeling; model testing and simulation output analysis.

The verification and validation of the simulation model are important for ensuring that the model built is right representation of the real system. The use of what-if is validated by the structure and data assumptions. Changing the waiting line style or the input data helps the validation of the model. The alternatives are simulated in the model after verification and validation of the simulation model.

The following parts of the paper are organized as follows. Section 2 provides an overview of the patient flow in the OR; the data collection is discussed in Section 3. Section 4 describes the simulation modeling and tools. Section 5 shows the model verification for the evaluation of the OR performance. Section 6 discusses the simulation output and analysis of different scenarios of OR operation followed by conclusions and further work in Section 7.

\section{Patients flow of the OR}

The OR department at WHSC works for surgeries of both elective and emergency patients. The elective slate runs from 7:30 to 15:30 from Monday to Friday each week. The emergency slate runs from 15:30 to 22:30, Monday to Friday, and usually has two staffed operating theatres. Of course very urgent emergency cases are still performed after 22:30.

On the weekends there is no elective slate and two operating theatres are staffed solely for emergency procedures. Some emergency patients who are not very urgent usually are handled in the elective slate as elective patients. This research will only consider the elective patients.

As shown in Figure 1, the patients flow starts from the registration. The patient is then picked from Preoperative unit and is sent to Inpatient Ward or other units after the surgery. It includes Post Anaesthesia Care Unit (PACU) and Surgical Intensive Care Unit (SICU).

Most patients are tested in Pre-operative units, such as X-ray and blood test units. The patient is also interviewed by an OR nurse, and is assessed by the anesthetist in the hold area (also called music room) before the surgery. After the operating room is ready, the patient is moved to the operating room. The OR nurse and anesthetists place the patient in the position and put the patient into sleep. The patient is taken to PACU or SICU to recovery after the surgery. The OR has the link to many other departments, such as Preoperative units and Inpatient departments. There are many factors influencing patients' surgery. If, for example, there are not enough beds in MS3, a preoperative unit in the hospital, the patient will not be arranged for the surgery. The elective patient types are listed in Table 1.

The OR resources considered include rooms, beds, front desk, hold area and others as listed in Table 2. Table 3 are resources related to the OR in WHSC. There are 13 rooms or beds in the OR department that are located in one floor as shown in Figure 2.

\section{Data collection of the $\mathrm{OR}$}

Data are essential for a simulation model. Table 4 is a preliminary list of data items used as input to the model based on the OR patient flow. These data are necessary to validate the simulation model. So far, five weeks elective patients' data are collected from WHSC. The total number of patients is 740 . Three tables are used in the database to record the collected data as shown in Figure 3.

\section{Simulation modeling}

A simulation model is built according to the patient flow in the OR. WITNESS software [13] is used as the simulation tool in this research. WITNESS has functions of visual, interactive, and interpretative modeling. It has features of friendly Graphical User Interface (GUI), and easy to learn with a modular and hierarchical structure. It also includes many useful 


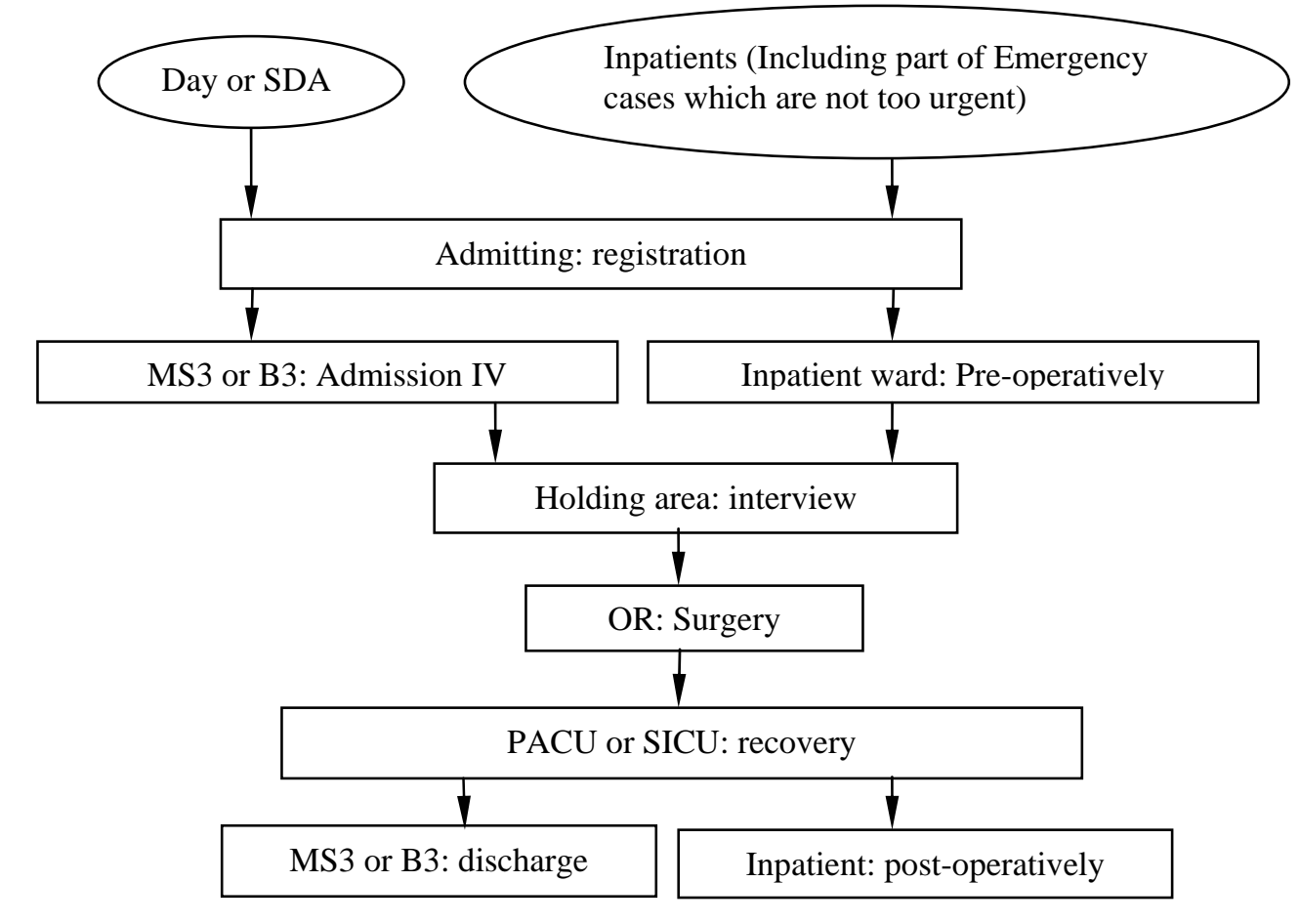

Figure 1. The elective patient flow at the OR department of WHSC

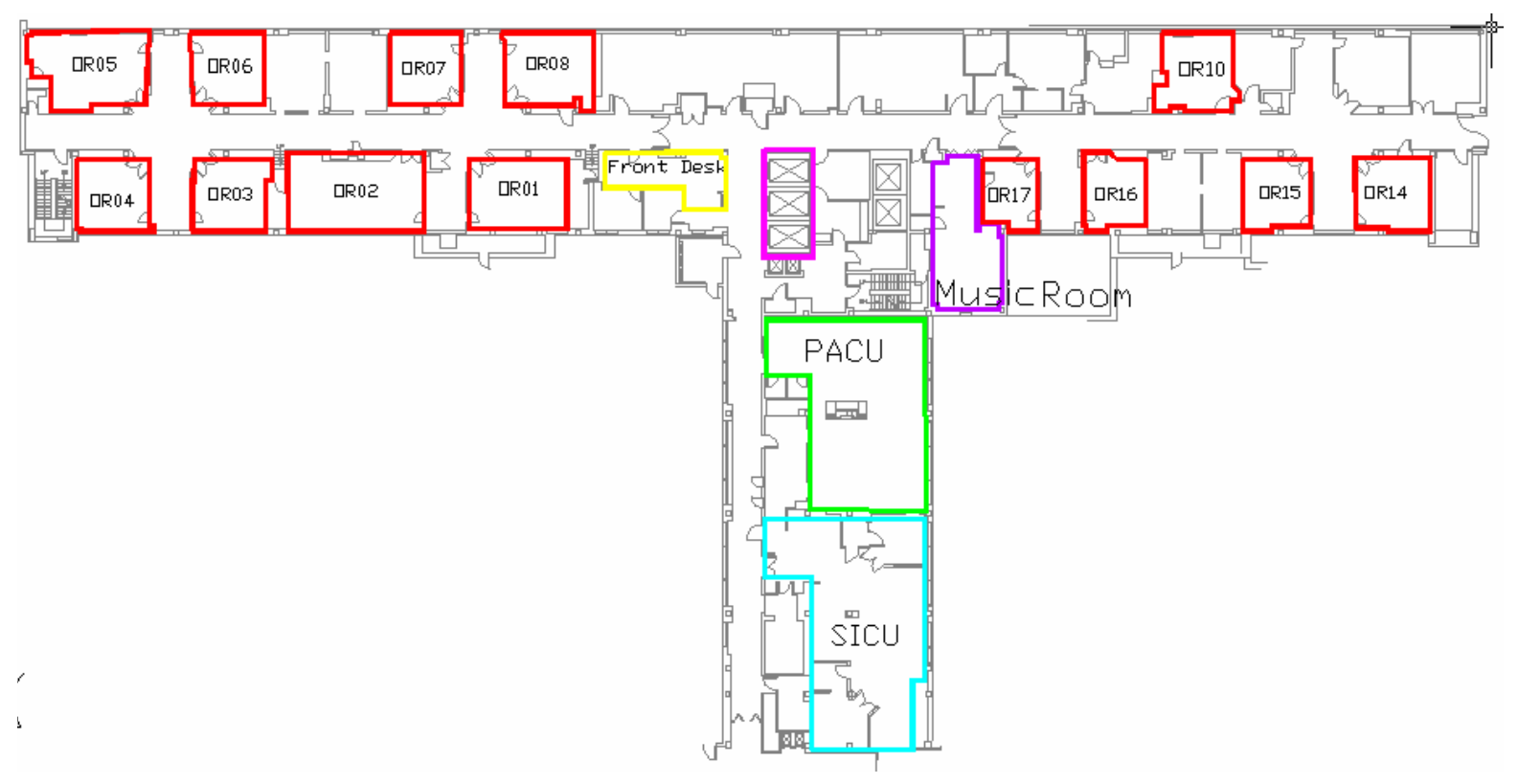

Figure 2. Layout of the OR department at WHSC 
Table 1. Elective patient types

\begin{tabular}{|l|l|l|}
\hline No. & Patient Type & Description \\
\hline 1 & SD & Same Day Patients \\
\hline 2 & SDA & Same Day Admission Patients \\
\hline 3 & INP & Inpatients \\
\hline
\end{tabular}

Table 2. The resources in OR

\begin{tabular}{|l|l|l|}
\hline No. & Items & Quantity \\
\hline 1 & Operating Rooms/beds & 13 \\
\hline 2 & Front desk & 1 \\
\hline 3 & Hold Area (Music room) & 6 chairs \\
\hline 4 & PACU & 12 beds \\
\hline 5 & Operating Room Nurses & 36 \\
\hline 6 & Perioperative Aides (Pas) & 3 \\
\hline 7 & Transport Personnel & 2 \\
\hline 8 & Anaesthetists & 12 \\
\hline 9 & IHA (Backup Anaesthetist) & 1 \\
\hline
\end{tabular}

Table 3. Resources related to the OR

\begin{tabular}{|l|l|l|}
\hline No. & Items & Quantity \\
\hline 1 & Admitting & 1 \\
\hline 2 & MS3 & 6 Beds \\
\hline 3 & B3 & 4 Beds \\
\hline 4 & Inpatient ward & 164 Beds \\
\hline
\end{tabular}

Table 4. A data list collected for the simulation model

\begin{tabular}{|l|l|}
\hline No. & Items \\
\hline 1 & The admitting time \\
\hline 2 & $\begin{array}{l}\text { The arrival time to pre-op units which are } \\
\text { MS3, B3, Inpatient ward }\end{array}$ \\
\hline 3 & The leave time from pre-op units \\
\hline 4 & The arrival time to OR \\
\hline 5 & The leave time from OR \\
\hline 6 & The arrival time to post-op units \\
\hline 7 & The discharge time \\
\hline 8 & The start time of OR setup \\
\hline 9 & The end time of OR setup \\
\hline 10 & The start time of OR cleaning \\
\hline 11 & The end time of OR cleaning \\
\hline
\end{tabular}

tools such as comprehensive statistical input and reports, linkage-databases, direct spreadsheet link in/out, XML formats and HTML reports. AutoCAD is used for drawing the OR layout in the simulation model. Python [14] is used for data operation and data analysis. It is a dynamic object-oriented programming language. Python offers a strong support for integration with other languages and tools. It comes with extensive standard libraries. Python is distributed under an OSI-approved open source license. The system variables in simulation model listed in Table 5 are used for the system performance analysis.

Table 5. Variables used in the model

\begin{tabular}{|c|c|c|}
\hline No & Item & Description \\
\hline 1 & No & The number of the patient \\
\hline 2 & ArrivalTime & The patient admitting time \\
\hline 3 & MRBegings & $\begin{array}{l}\text { The time when the patient } \\
\text { arrives at the holding area }\end{array}$ \\
\hline 4 & OPBegins & The time when the OR begins \\
\hline 5 & OPEnds & The time when the OR ends \\
\hline 6 & PACUBegins & $\begin{array}{l}\text { The time when the patient } \\
\text { arrives to PACU }\end{array}$ \\
\hline 7 & LeaveTime & $\begin{array}{l}\text { The time when the patient } \\
\text { discharges }\end{array}$ \\
\hline 8 & LOS & The length of stay \\
\hline 9 & count & $\begin{array}{l}\text { The count in the simulation } \\
\text { model }\end{array}$ \\
\hline
\end{tabular}

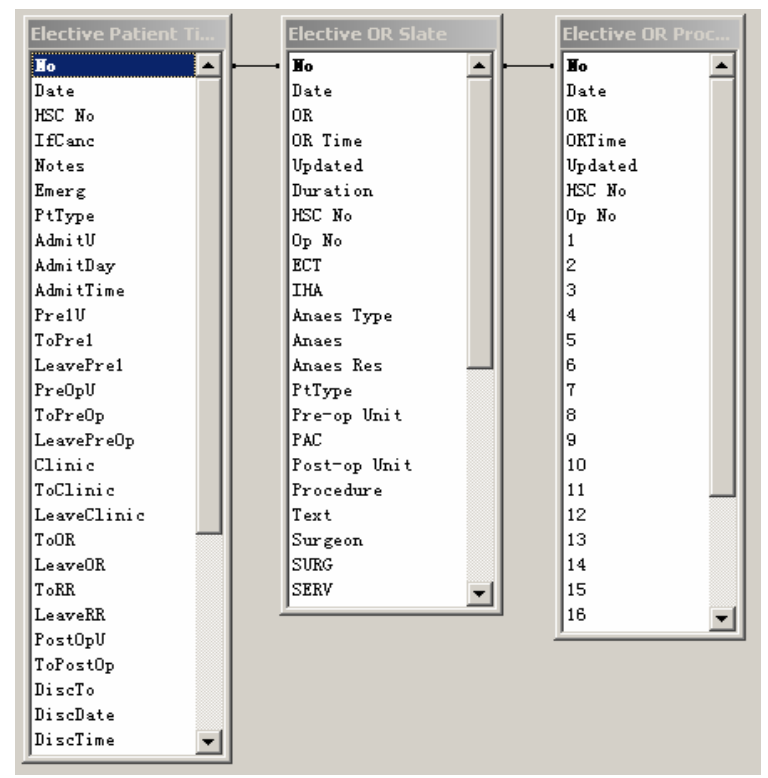

Figure 3. Tables in the database to record the collected data

Figure 4 is a Histogram that shows the distribution of the surgery processing time based on the collected date of the OR. Distribution functions are used to generate the processing time based on the analysis of the collected data and the statistical test. The 
distributions used in the modeling are listed in Tables 6 and 7.

Therefore, the OR scheduling can be modeled based on the definition of variables and data generated by the distribution functions as shown in Figure 5. The scheduling is generated using Python to query the elective_patient_time table in the database. The input data are imported into the WITNESS simulation model using text files. The processed data are written in output files. Python reads data from these files, and implements all functions needed in the processing. Python is also connected to a Microsoft Access database to record all patient information. Python retrieves data from the database to analyze data and to generate the distributions.

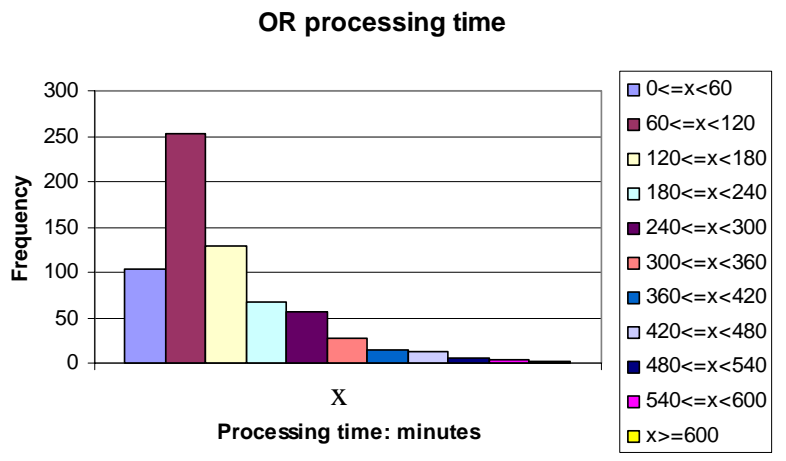

Figure 4. The histogram of surgery processing time

Table 6. Main distributions of processing time (unit: minutes)

\begin{tabular}{|l|l|l|}
\hline Items & Time & Place \\
\hline $\begin{array}{l}\text { Patient } \\
\text { arrival }\end{array}$ & PatientArrival (13) & Admitting \\
\hline Admitting & $\begin{array}{l}\text { UNIFORM } \\
(2,10,4)\end{array}$ & Admitting \\
\hline Interview & NEGEXP(10,10) & Holding area \\
\hline Assessment & NEGEXP(10,11) & Holding area \\
\hline Surgery & Duration (12) & $\begin{array}{l}\text { Operating } \\
\text { Room }\end{array}$ \\
\hline Recovery & $\begin{array}{l}\text { TRIANGLE } \\
(0,144,657,6)\end{array}$ & PACU \\
\hline OR cleaning & $\begin{array}{l}\text { TRIANGLE } \\
(0,14,28,19)\end{array}$ & $\begin{array}{l}\text { Operating } \\
\text { Room }\end{array}$ \\
\hline OR setup & $\begin{array}{l}\text { TRIANGLE } \\
(0,15,36,20)\end{array}$ & $\begin{array}{l}\text { Operating } \\
\text { Room }\end{array}$ \\
\hline
\end{tabular}

The patient models are built with different types, and attributes are utilized in collecting and recording data of waiting and total time spent in the OR. Histograms are defined to display waiting time and total time of patients. A screen shot of the simulation model is shown in Figure 6. Figure 7 shows attributes and variables in the simulation model.

\section{Table 7. Travel time between different units (unit: minutes)}

\begin{tabular}{|l|l|}
\hline From- to & Distributions \\
\hline Pre-op units to OR & TRIANGLE $(0,21,41,1)$ \\
\hline OR to PACU & TRIANGLE $(0,4,10,20)$ \\
\hline PACU to post-op unit & TRIANGLE $(0,8,24,2)$ \\
\hline
\end{tabular}

\section{Model testing}

The model testing is the verification and validation of the simulation model. Verification and validation make sure that the model built is right for the basic test of the simulation model. The key of the model verification is to guarantee the assumptions of the conceptual model are right and close to the reality.

The model performances are compared between the reality and model results by running 6 replications for five weeks of each replication. The data in Table 8 show that the simulation results are very close the reality of the collected actual data.

\section{Model running and the simulation analysis}

The simulation model enables scenarios to analyze how observed variables in the OR will be affected by the data or resources change. By changing some of inputs, the model is able to show how the performance is automatically changed when resources and other pertinent data are revised.

Based on the data collected from five weeks, the model running lengths and warm up periods of 25 days, and 3 days respectively are used for each replication to allow for the system to reach realistic operating conditions before collecting appropriate statistics. 6 replications of the simulation have been undertaken.

Simulation is run based on different scenarios. The overall utilization rates for each case can be displayed for doctors, nurses and beds. The length of stay of patients in the OR is simulated. It is assumed that a fully loaded one week appointment book as input for the simulation. The simulation shows the detailed daily operations with patient arrivals and resource constraints. 


\section{Definition of attributes:}

The first column is the patient type

The second column is the quantity of arrival patient

The third column is the time when the patient arrives

ORNo $=$ The number of operating room

Duration $=$ The surgery processing time

No $=$ The No of the patient

PreOP $=$ Pre-operative unit

PostOP $=$ Post-operative unit

$P A C=$ If patient went to PAC or not before surgery, 1 means that patient went to PAC before the surgery.

\section{Part of scheduling file:}

\begin{tabular}{|c|c|c|c|c|c|c|c|}
\hline$\overline{I N P}$ & 1 & 365 & $O R N o=8$ & Duration $=241$ & $N O=1$ & PreOP="D2" & \\
\hline$S D A$ & 1 & 373 & $O R N o=1$ & Duration $=295$ & $N O=2$ & PreOP="GMS3" PostOP="A3" & $P A C=1$ \\
\hline$S D A$ & 1 & 373 & $O R N o=2$ & Duration $=296$ & $N O=3$ & PreOP="GMS3" PostOP="A3" & $P A C=1$ \\
\hline$S D$ & 1 & 394 & $O R N o=16$ & Duration $=124$ & $N O=4$ & PreOP="GMS3" & \\
\hline$S D A$ & 1 & 410 & $O R N o=3$ & Duration $=242$ & $N O=5$ & PreOP="GMS3" PostOP="D2" & $P A C=1$ \\
\hline$S D$ & 1 & 428 & $O R N o=15$ & Duration $=63$ & $N O=6$ & PreOP="GB3" & \\
\hline
\end{tabular}

Figure 5. The part of a OR scheduling

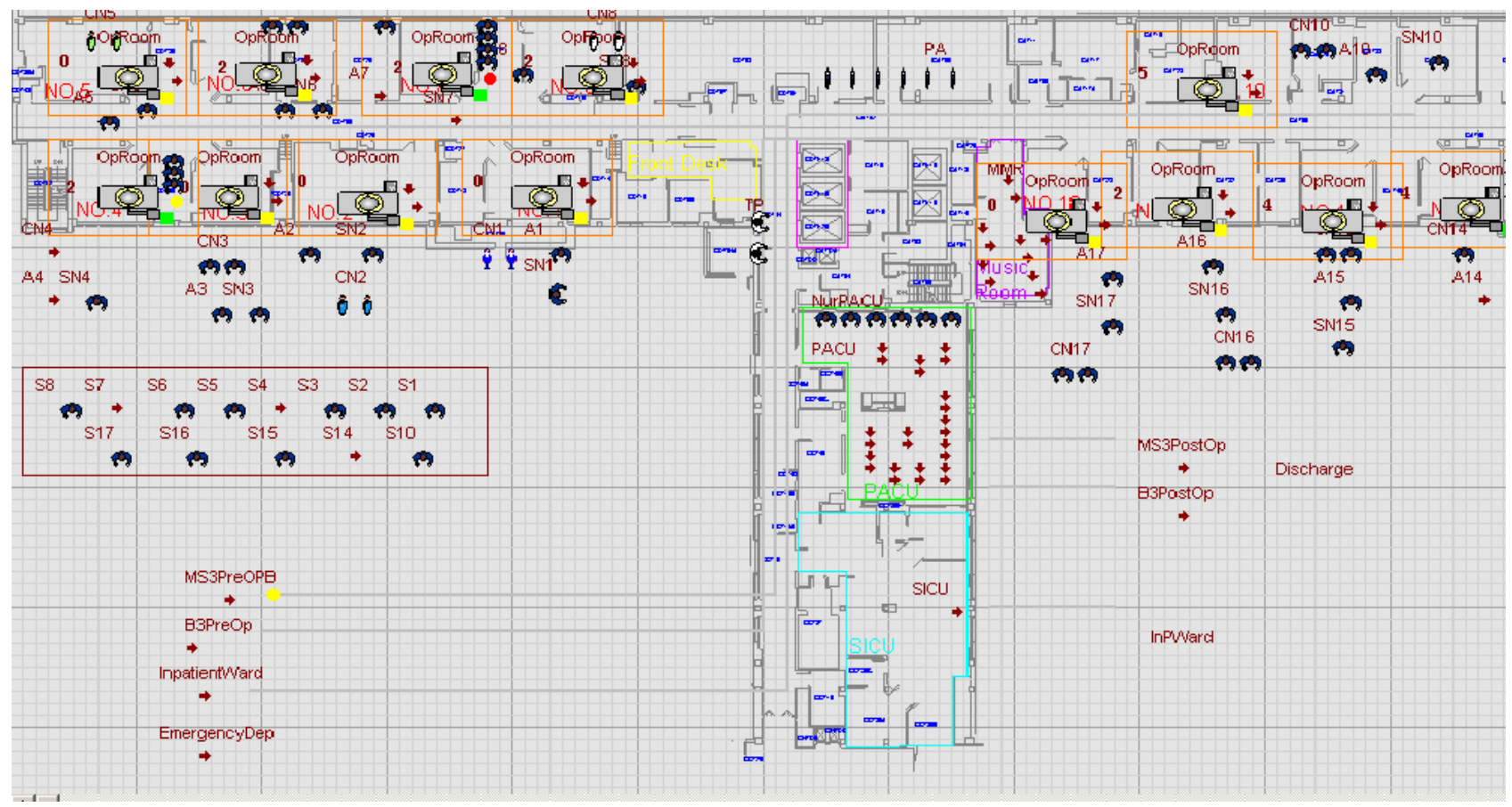

Figure 6. A screen shot of the simulation model 


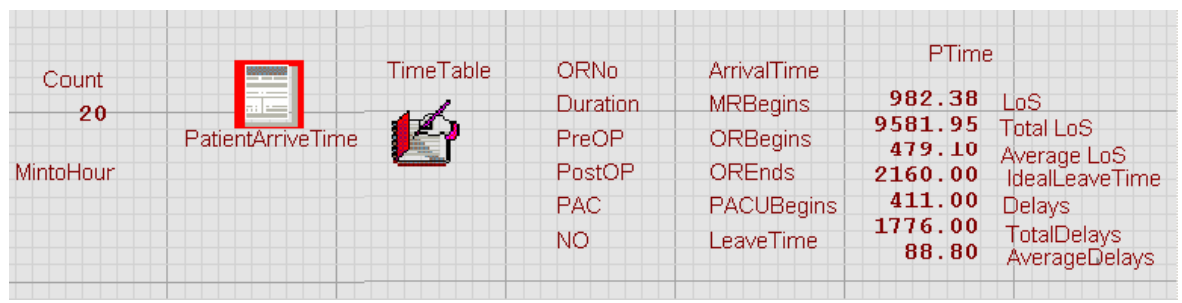

Figure 7. Attributes and variables in the simulation model

Table 8. The model validations

\begin{tabular}{|l|l|l|l|}
\hline No & Items & Reality & Simulation results \\
\hline 1 & Patient count of each day & 26 & 27 \\
\hline 2 & Average length of stay for SD patients & 901 minutes & 923.0 minutes \\
\hline 3 & Average length of stay for SDA patients & 6063 minutes & 6130.0 minutes \\
\hline 4 & Average length of stay for inpatients & 23401 minutes & 23560.0 minutes \\
\hline 5 & Average busy time of OR each day & 421 minutes & 413 minutes \\
\hline 6 & Cancellation cases of week day & 7 cases & 6 cases \\
\hline
\end{tabular}

Table 9. The comparison of the resources change

\begin{tabular}{|c|c|c|c|c|c|c|c|c|c|}
\hline \multirow{2}{*}{ No } & \multicolumn{3}{|c|}{ Resources } & \multicolumn{2}{c|}{ SD } & \multicolumn{2}{c|}{ SDA } & \multicolumn{2}{c|}{ Inpatient } \\
\cline { 2 - 10 } & Beds in OR & $\begin{array}{c}\text { Beds in } \\
\text { PACU }\end{array}$ & $\begin{array}{c}\text { Chairs in } \\
\text { holding area }\end{array}$ & $\begin{array}{c}\text { Average } \\
\text { LOS }\end{array}$ & Change & $\begin{array}{c}\text { Average } \\
\text { LOS }\end{array}$ & Change & $\begin{array}{c}\text { Average } \\
\text { LOS }\end{array}$ & Change \\
\hline 1 & 13 & 12 & 6 & 923.0 & 0 & 6130.0 & 0 & 23560.0 & 0 \\
\hline 2 & 13 & 12 & 10 & 865.0 & $6 \%$ & 5993.0 & $2 \%$ & 23298.0 & $4 \%$ \\
\hline 3 & 13 & 14 & 10 & 791.0 & $14 \%$ & 5901.0 & $8 \%$ & 23123.0 & $9 \%$ \\
\hline 4 & 14 & 14 & 10 & 717.0 & $22 \%$ & 5843.0 & $14 \%$ & 22986.0 & $17 \%$ \\
\hline
\end{tabular}

Table 10. Changing the number of TPs

\begin{tabular}{|c|c|c|c|c|c|c|c|}
\hline \multirow{2}{*}{ No } & \multirow{2}{*}{$\begin{array}{c}\text { Number of } \\
\text { TPs }\end{array}$} & \multicolumn{2}{|c|}{ SD patients } & \multicolumn{2}{c|}{ SDA patients } & \multicolumn{2}{c|}{ Inpatients } \\
\cline { 3 - 8 } & LOS & Change & $\begin{array}{c}\text { Average } \\
\text { LOS }\end{array}$ & Change & $\begin{array}{c}\text { Average } \\
\text { LOS }\end{array}$ & Change \\
\hline 1 & 2 & 923.0 & 0 & 6130.0 & 0 & 23560.0 & 0 \\
\hline 2 & 3 & 901.0 & $2.30 \%$ & 6102.0 & $0.46 \%$ & 23536.0 & $0.10 \%$ \\
\hline 3 & 5 & 853.0 & $7.60 \%$ & 6062.0 & $3.20 \%$ & 23494.0 & $2.01 \%$ \\
\hline 4 & 7 & 793.0 & $14.00 \%$ & 5989.0 & $7.60 \%$ & 23382.0 & $5.04 \%$ \\
\hline
\end{tabular}

LOS of SD patients

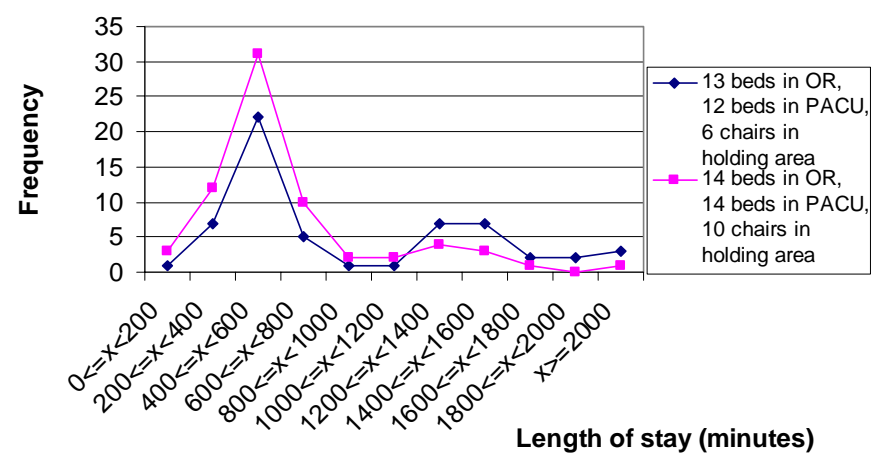

Figure 8. Reduced LOS of SD patients 
The experimental data created includes the arrival time of the patient and the category of the patient. Preliminary simulation experiments indicate that when more patients are expected to be processed at the OR, the patient waiting time would become longer, unless the additional beds are allocated. Then, a stepwise procedure of operations planning is proposed to reduce the patient waiting time. Through a series of simulation experiments, the patient waiting time can be minimized, by adjust appropriate resources in the OR.

Table 9 shows the average length of stay (LOS) of different patients and the reduced ratio of LOS under different resource conditions. The assumed resources changes used in the simulation include the number of the beds in PACU, the number of the OR rooms, and the number of chairs in holding area. Figure 8 shows the reduced LOS of SD patients with the resources of row No. 4 comparing with using the resources of row No. 1 in Table 9. It shows in Figure 8 that the frequency of short stay $(0<x<1400)$ is increased and the frequency of long stay is decreased $(x>1400)$.

Table 10 shows the improvement when increasing the number of transport personals (TPs). Patients are transported to operating room almost at the same time in the morning as all operating rooms are empty. Currently, there are only two TPs who move patients from the pre-op unit to the operating room.

\section{Conclusions and further work}

This research shows that simulation is an efficient tool for identifying problems and improving performance of healthcare systems. The simulation model is valuable to present the current work flow and to predict the bottleneck in healthcare systems. The simulation model developed initially demonstrates that the resources in the OR department of WHSC is a main bottleneck for the longer stay of patients in the hospital.

In this research, simulation models provide a reasonable assessment of OR's efficiency, resource utilizations and other performance measures. By using the simulation, a useful evaluation for the OR provides a chance to analyze and improve the current operation processing. The output of the simulation shows the analysis result with a verity of formation. The graphical user interface provides an effective tool for decision-making of the OR operation.

Further work is to optimize the simulation model based on the existing OR resources. More data will be collected to complete the model. The emergency patients cases in the OR department will also be considered.
The work described in this paper is an initial step for the OR improvement. The simulation of healthcare is different from manufacturing simulation which mainly deals with the material flow. Healthcare is a humancentered system including doctors, nurses, patients, and assistants. Human behaviours are different from those of machines. The future work will also emphasize human behaviours in healthcare systems.

\section{Acknowledgments}

This research is supported by Winnipeg Regional Health Authority and Winnipeg Health Science Centre. Thanks for the support of staff members at WHSC for the data collection and comments for the simulation model. Thanks Drs. Michael Moffatt and Brock Wright for their support and comments for this research project.

\section{References}

[1] C. D. Barnes, J. L. Quiason, C. Benson, and D. McGuiness, "Success Stories in Simulation in Health Care", Proceedings of the 1997 Winter Simulation Conference, pp. 1280-1285.

[2] J. C. Lowery, B. Hakes, W. R. Lilegdon, L. Keller, K. Mabrouk, and F. McGuire, "Barriers to Implementing Simulation in Health Care", Proceedings of the 1994 Winter Simulation Conference, pp. 868-875.

[3] M. A. Centeno, R. Giachetti, R. Linn, and A. M. Ismail, "A Simulation-ILP based Tools for Scheduling ER Staff”, Proceedings of the 2003 Winter Simulation Conference, pp. 1930-1938.

[4] B. P. Morrison and B. C. Bird, "A Methodology for Modeling Front Office and Patient Care Processes in Ambulatory Health Care”, Proceedings of the 2003 Winter Simulation Conference, pp. 1882-1886.

[5] S. Takakuwa and H. Shiozaki, "Functional Analysis for Operating Emergency Department of a General Hospital”, Proceedings of the 2004 Winter Simulation Conference, pp. 2003-2011.

[6] F. F. Baesler, H. E. Jahnsen, and M. DaCosta, "The Use of Simulation and Design of Experiments for Estimating Maximum Capacity in An Emergency Room”, Proceedings of the 2003 Winter Simulation Conference, pp. 1903-1906.

[7] J. J. Abellán, C. Armero, and et al., "Predicting the Behavior of the Renal Transplant Waiting List in the Pais Valencia (Spain) Using Simulation Modeling”, Proceedings of the 2004 Winter Simulation Conference, pp.1969-1974.

[8] M. Guo, M. Wagner, and C. West, Outpatient Clinic Scheduling - A Simulation Approach, Proceedings of the 2004 Winter Simulation Conference, pp. 1981-1987.

[9] V. Z. Osidach, and M. C. Fu, "Computer Simulation of a Mobile Examination Centre", Proceedings of the 2003 Winter Simulation Conference, pp.1868-1875.

[10] A. Wiinamaki and R. Dronzek, "Using simulation in the architectural concept phase of an emergency 
department design”, Proceedings of the 2003 Winter Simulation Conference, p1912-1916.

[11] S. Samaha, W. S. Armel and D. W. Starks, "The Use of Simulation to Reduce the Length of Stay in an Emergency Department”, Proceedings of the 2003 Winter Simulation Conference, pp. 1907-1911.

[12] R. E. Blasak and W. S. Armel, "The Use of Simulation to Evaluate Hospital Operations Between The Emergency Department And a Medical Telemetry Unit”, Proceedings of the 2003 Winter Simulation Conference, pp. 1887-1893.

[13] www.lanner.com

[14] http://www.python.org/ 